\title{
Syntesis and charachterization of metallo-drugs with potential use for overweight treatment
}

\author{
D’Vries, Richard Fernando; ${ }^{1}$ Villamizar, Stephanny; ${ }^{1}$ Porras, Laura Maria; ${ }^{1}$ Piñeros, Octavio; ${ }^{1}$ Ellena, Javier ${ }^{2}$ \\ ${ }^{1}$ Facultad de Ciencias Básicas, Universidad Santiago de Cali, Calle 5 \# 62-00, Cali, Colombia. \\ ${ }^{2}$ Instituto de Física de São Carlos, Universidade de São Paulo, CP. 369, 13560-970, São Carlos - SP, Brasil. \\ richard.dvries00@usc.edu.co
}

The transition metals, specifically biometals such as $\mathrm{Co}, \mathrm{Cu}, \mathrm{Zn}$ and $\mathrm{Ni}$, are being the target of numerous scientific studies from different branches of chemistry, medicine and pharmacology. These metals are well known to form bonds and interactions with biomolecules. Also, are often responsible for the biological function of biomolecules in the body, are immersed in many biochemical processes essential for life. In addition, these metal cations have a great tendency to form coordination compounds with numerous types of ligands. Into the medical-pharmacological field is the medicinal inorganic chemistry that explores binding agents with therapeutic properties linked to metal cations and their multiple applications. ${ }^{1,2}$

this work focuses on the synthesis, characterization and structural study of complexes based on metformin and transition metals as $\mathrm{Co}(\mathrm{II}), \mathrm{Cu}(\mathrm{II}), \mathrm{Ni}(\mathrm{II})$ and $\mathrm{Zn}(\mathrm{II})$, in order to propose new therapeutic alternatives, by taking advantage of the characteristics of current drugs in synergy with the activity of metallic cations. ${ }^{3}$

[1] A. Sigel, H. Sigel, E. Freisinger and R. K. O. Sigel, Metallo-Drugs: Development and Action of Anticancer Agents, DeGruyter, Z"urich, 2018.

[2] S. A. Fine and K. J. Kinsella, US Pat., US20070196512A1, 1998.

[3] Stephanny Villamizar-Delgado, Laura M Porras-Osorio, Octavio Piñeros, Javier Ellena, Norman Balcazar, Ruben E Varela-Miranda, Richard F D'Vries. Biguanide-transition metals complexes as potential drug for hyperglycemia treatment. RSC Adv. 2020, 10 (38), $22856-22863$.

Keywords: Metallo-Drug, cytotoxicity, biguanide 